\title{
Electrical and Magnetic Properties - Structure Correlation on $\mathrm{Nd}_{0.65} \mathrm{Sr}_{0.35} \mathrm{Mn}_{1-X} \mathrm{Fe}_{X} \mathrm{O}_{3}$
}

\author{
I. A. Abdel-Latif ${ }^{1 *}$, A. S. Khramov ${ }^{2}$, V. A. Trounov ${ }^{3}$, O. P. Smirnov ${ }^{3}$, \\ Sh. Sh. Bashkirov ${ }^{2}$, V. V. Parfenov ${ }^{2}$, E. A. Tserkovnaya ${ }^{3}$, \\ G. G. Gumarov ${ }^{2,4}$ and Sh. Z. Ibragimov ${ }^{5}$ \\ ${ }^{1)}$ Reactor Physics Dept., NRC, Atomic Energy Authority, Abou Zabaal P. \\ O. 13759, Cairo, Egypt \\ 2) Faculty of physics, Kazan State University, Kazan, 420008, Russia \\ 3) PNPI, RAS, Gatchina, Petersburg, Russia \\ 4) Kazan physical-technical Institute of RAS, Kazan, Russia \\ ${ }^{5)}$ Faculty of geology, Kazan State University, Kazan, 420008, Russia
}

The present paper deals with studying the magnetic and the electrical properties - structure correlation of compounds under investigation: $\mathrm{Nd}_{0.65} \mathrm{Sr}_{0.35} \mathrm{Fe}_{x} \mathrm{Mn}_{1-\mathrm{x}} \mathrm{O}_{3}(x=0.2,0.4,0.6$ and 0.8). All samples are prepared using standard solid state reaction method and tested using $X$-ray and neutron diffraction. They have orthorhombic distortion perovskite-like structure of space group Pnma. It is found that the activation energy is directly proportional to the volume of unit cell. The crystal structure does not change with changing the concentration of iron where all the samples have the same space group. The transition from the pure ferromagnetic ordering into the non-collinear ordering (weak ferromagnetic) occurs at $520 \mathrm{~K}$ for $\mathrm{Nd}_{0.65} \mathrm{Sr}_{0.35} \mathrm{Fe}_{0.6} \mathrm{Mn}_{0.4} \mathrm{O}_{3}$.

\section{Introduction:}

During the last few decades the world scientific attention was concentrated on studying the unusual magnetic and electric properties of perovskite manganese oxides $R_{y} A_{1-y} M O_{3}$, where $R$ is a rare earth element, $A$ is a divalent element like $\mathrm{Ca}, \mathrm{Sr}, \mathrm{Ba}$ and $M$ is a transition metal element. These compounds could be used as a magnetic storage media. As it is well-known the rare earth orthoferrites, orthomanganite, orthonicklite crystallize with orthorhombic distortion of the perovskite structure [1]. The $R$ sites are surrounded by quite distorted 12 oxygen atoms polyhedra while the oxygen

\footnotetext{
*E-mail address: ihab abdellatif@vahoo.co.uk
} 
octahedral around the $M$ ones are less distorted. In 1950 the striking correlation between magnetic order and conductivity was discovered $[2,3]$ and it was the beginning for further research to understand such a correlation. After that the concept of double exchange was suggested by Zener [4]. When some of the $R^{3+}$ is replaced by $A^{2+}$, part of the $\mathrm{M}$ element will transform to tetravalent such that this $M^{4+}$ is equivalent to the value of $A^{2+}$. Electronic exchange between $M^{4+}$ and $\mathrm{M}^{3+}$ ions occurs via oxygen ions and these electrons have the same spins so the compound becomes ferromagnetic and conducting. It's too important to find a correlation between the crystal structure and electrical and magnetic parameters.

The present paper is devoted to find the correlation between the magnetic and electrical properties and crystal structure of $\mathrm{Nd}_{0.65} \mathrm{Sr}_{0.35} \mathrm{Fe}_{x} \mathrm{Mn}_{1-x} \mathrm{O}_{3}$.

\section{Experimental Details:}

The $\mathrm{Nd}_{0.65} \mathrm{Sr}_{0.35} \mathrm{Fe}_{x} \mathrm{Mn}_{1-x} \mathrm{O}_{3}$ samples were prepared using standard solid solution reaction method from the following oxides: $\mathrm{SrO}, \mathrm{Nd}_{2} \mathrm{O}_{3}, \mathrm{Fe}_{2} \mathrm{O}_{3}$ and $\mathrm{Mn}_{2} \mathrm{O}_{3}$. These oxides were carefully mixed, milled and pressed in rectangular form then calcined at a temperature of $1040{ }^{\circ} \mathrm{C}$ for $8 \mathrm{~h}$. After that, the obtained compound milled and pressed again to be burned at a temperature of $1150{ }^{\circ} \mathrm{C}$ for $8 \mathrm{~h}$. Finally the last process was repeated but the firing (sintering) temperature was $1200{ }^{\circ} \mathrm{C}$ for $8 \mathrm{~h}$. The burning was done at the air environment. The full profile X-ray analysis was done on DRON-3 X-ray powder diffractometer. The neutron diffraction measurements were carried out only for $\mathrm{Nd}_{0.65} \mathrm{Sr}_{0.35} \mathrm{Fe}_{0.6} \mathrm{Mn}_{0.4} \mathrm{O}_{3}$ sample using Mini-Sfinks and multi-detector diffractometer (PNPI, Gatchina, Russia). The software used in X-ray and neutron diffraction analysis was MRIA [5] and FULLPROOF [6] programs. The resistivity temperature dependence was measured using standard four probe method. Magnetization temperature dependence measurements were carried out using Faraday's method in the temperature range from 95 to $973 \mathrm{~K}$.

\section{Results and Discussion:}

The X-ray diffraction analysis as well as the neutron diffraction and MÖssbauer spectroscopy [7] analysis approved the formation of a single phase structure of the samples. The experimentally obtained density of such samples compared with those defined by X-ray is in the range of $88-90 \%$, thus the porosity is of the range $10-12 \%$, (in the acceptable range).

The lattice parameters of all samples are given in Table (1) and the neutron diffraction pattern of $\mathrm{Nd} 0.65 \mathrm{Sr} 0.35 \mathrm{Mn} 0.4 \mathrm{Fe} 0.6 \mathrm{O} 3$ is shown in Fig (1). All spectra are refined according to space group Pnma where the $\mathrm{Nd} / \mathrm{Sr}$ atoms 
have $(\mathrm{x}, 1 / 4, \mathrm{z})$ coordinates and the $\mathrm{Fe} / \mathrm{Mn}$ atoms have $(0,0,1 / 2)$ coordinates. Concerning the oxygen atoms; four of them occupy the $(x, 1 / 4, z)$ coordinates and eight have $(\mathrm{x}, \mathrm{y}, \mathrm{z})$ coordinates. The $\mathrm{x}$ and $\mathrm{z}$ of $\mathrm{Nd} / \mathrm{Sr}$ atoms have values from 0.024 and 0.002 to 0.071 and 0.033 , respectively while their values for $\mathrm{O}(1)$ atoms vary from 0.495 and 0.001 to 0.642 and 0.042 , respectively. The $\mathrm{O}(2)$ atoms coordinates $\mathrm{x}, \mathrm{y}$ and $\mathrm{z}$ are in the range from $-0.251,0.001,0.221$ to $-0.345,0.033,0.353$, respectively. The refined thermal parameters, obtained from the analysis of X-ray diffraction patterns, are anisotropic for all $\mathrm{x}$, Table (2). The quality factors of the refinements are listed in Table (3). The obtained lattice parameters, positional and thermal parameters are in a good agreement with those given in the literature for similar compounds $[8,9]$. The crystal structure does not change with changing the concentration of iron as all the samples have the same space group.

Table 1. Cell parameters $(\AA)$ and volume $\left(\AA^{3}\right)$ for $\mathrm{Nd}_{0.65} \mathrm{Sr}_{0.35} \mathrm{Mn}_{1-x} \mathrm{Fe}_{x} \mathrm{O}_{3}$.

\begin{tabular}{|c||c|c|c|c||}
\hline $\mathrm{x}$ & $\mathrm{a}$ & $\mathrm{b}$ & $\mathrm{c}$ & $\mathrm{V}$ \\
\hline \hline 0.2 & $5.4726(9)$ & $7.6776(13)$ & $5.4361(8)$ & $228.406(3)$ \\
\hline 0.4 & $5.4527(8)$ & $7.7283(10)$ & $5.4441(8)$ & $229.415(3)$ \\
\hline 0.6 & $5.4638(5)$ & $7.7413(6)$ & $5.4560(5)$ & $230.772(2)$ \\
\hline 0.6 & $5.4627(2)$ & $7.7297(2)$ & $5.4573(1)$ & $230.435(1)$ \\
\hline 0.8 & $5.5249(14)$ & $7.7210(17)$ & $5.4622(17)$ & $233.005(5)$ \\
\hline
\end{tabular}

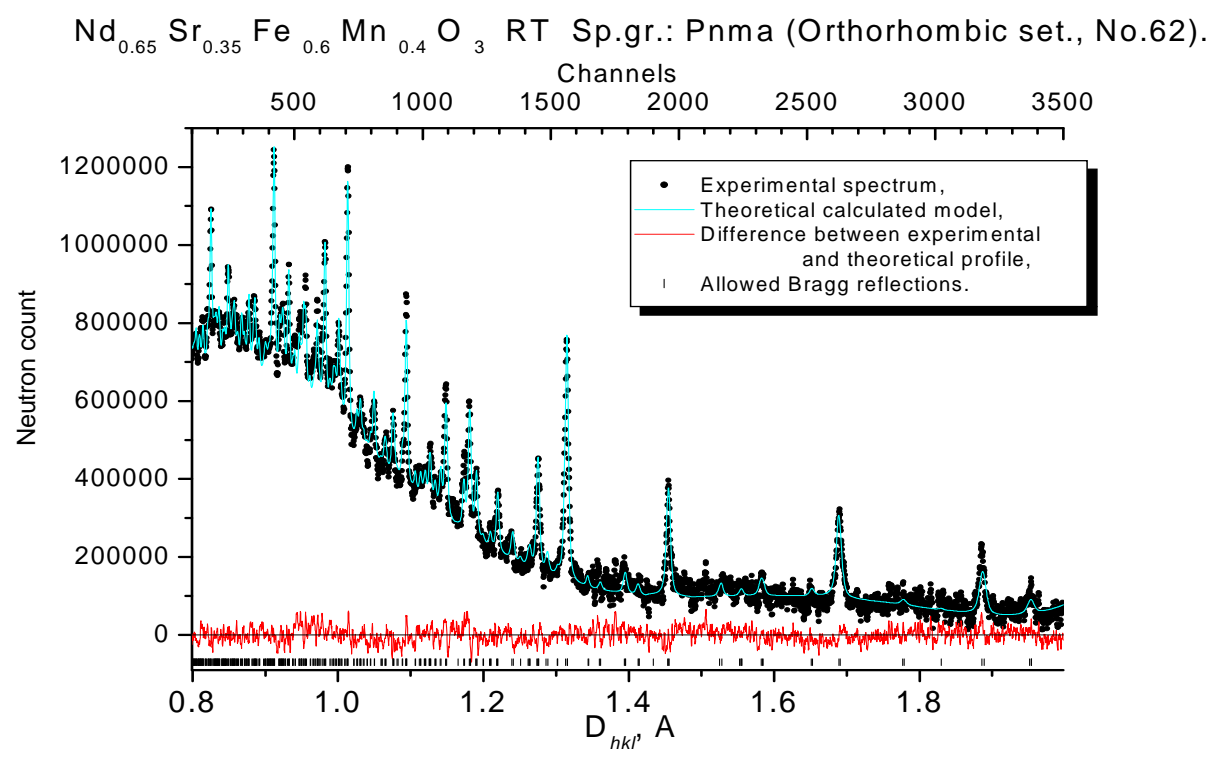

Fig.(1): Neutron diffraction pattern of $\mathrm{Nd}_{0.65} \mathrm{Sr}_{0.35} \mathrm{Fe}_{0.6} \mathrm{Mn}_{0.4} \mathrm{O}_{3}$ at room temperature. 
Table (2): Thermal parameters of $\mathrm{Nd}_{0.65} \mathrm{Sr}_{0.35} \mathrm{Mn}_{1-\mathrm{x}} \mathrm{Fe}_{\mathrm{x}} \mathrm{O}_{3}$

\begin{tabular}{|c|c|c|c|c|c|}
\hline $\mathbf{U}_{\mathrm{ij}}$ & $\mathbf{x}$ & $\mathrm{Nd} / \mathrm{Sr}$ & Fe/Mn & 01 & $\mathrm{O} 2$ \\
\hline \multirow{4}{*}{$\mathrm{U}_{12}$} & 0.2 & $0.0305(13)$ & $0.0121(7)$ & $0.0880(5)$ & $0.0701(9)$ \\
\hline & 0.4 & $0.0102(20)$ & $0.0088(11)$ & $0.0354(3)$ & $0.0657(37)$ \\
\hline & 0.6 & $0.0149(9)$ & $0.0937(5)$ & $0.0299(12)$ & $0.0960(70)$ \\
\hline & 0.8 & $0.0106(17)$ & $0.0601(10)$ & $0.0957(5)$ & $0.0710(19)$ \\
\hline \multirow{4}{*}{$\mathrm{U}_{22}$} & 0.2 & $0.0048(30)$ & $0.0062(18)$ & $0.0430(21)$ & $0.0360(41)$ \\
\hline & 0.4 & $0.0062(12)$ & $0.0049(15)$ & $0.0155(18)$ & $0.0327(13)$ \\
\hline & 0.6 & $0.0075(7)$ & $0.0047(10)$ & $0.0149(5)$ & $0.0477(3)$ \\
\hline & 0.8 & $0.0054(9)$ & $0.0031(6)$ & $0.0470(11)$ & $0.0340(13)$ \\
\hline \multirow{4}{*}{$\mathrm{U}_{33}$} & 0.2 & $0.0105(21)$ & $0.0123(11)$ & $0.0430(9)$ & $0.0360(19)$ \\
\hline & 0.4 & $0.0117(22)$ & $0.0087(15)$ & $0.0155(11)$ & $0.0327(12)$ \\
\hline & 0.6 & $0.0150(21)$ & $0.0094(13)$ & $0.0149(11)$ & $0.0477(15)$ \\
\hline & 0.8 & $0.0109(19)$ & $0.0031(14)$ & $0.0470(18)$ & $0.0340(14)$ \\
\hline \multirow{4}{*}{$\mathrm{U}_{12}$} & 0.2 & 0 & 0 & 0 & 0 \\
\hline & 0.4 & 0 & 0 & 0 & $0.0058(15)$ \\
\hline & 0.6 & 0 & 0 & 0 & 0 \\
\hline & 0.8 & 0 & 0 & 0 & 0 \\
\hline \multirow{4}{*}{$\mathrm{U}_{13}$} & 0.2 & $0.2787(138)$ & 0 & 0 & 0 \\
\hline & 0.4 & $-0.0365(37)$ & 0 & 0 & $0.0006(50)$ \\
\hline & 0.6 & 0 & 0 & 0 & 0 \\
\hline & 0.8 & 0 & 0 & 0 & $-0.0085(35)$ \\
\hline \multirow{4}{*}{$\mathrm{U}_{23}$} & 0.2 & 0 & 0 & 0 & 0 \\
\hline & 0.4 & 0 & 0 & 0 & -0.0038 (19 \\
\hline & 0.6 & 0 & 0 & 0 & 0 \\
\hline & 0.8 & 0 & 0 & 0 & 0 \\
\hline
\end{tabular}

Table (3): The quality factors of refinements.

\begin{tabular}{|c||c|c|c|c|c||}
\hline $\mathbf{x}$ & $\mathbf{0 . 2}$ & $\mathbf{0 . 4}$ & $\mathbf{0 . 6}$ & $\mathbf{0 . 6}^{*}$ & $\mathbf{0 . 8}$ \\
\hline \hline$\chi^{2}$ & 1.798 & 1.559 & 2.882 & 1.905 & 1.674 \\
\hline$R_{p}$ & 4.66 & 4.37 & 4.6 & 6.82 & 4.55 \\
\hline$R_{b}$ & 65.82 & 73.63 & 51.65 & 40.43 & 63.29 \\
\hline$R_{w}$ & 6 & 5.69 & 6.08 & 6.58 & 5.96 \\
\hline$R_{e}$ & 4.65 & 4.53 & 3.63 & 6.38 & 4.78 \\
\hline
\end{tabular}

The temperature dependence of electrical resistivity is shown in Fig. (2). It is noted that these compounds have the semiconducting behavor and the increase of iron concentration leads to a decrease in conductivity [10]. From Fig. (2), it noted that the linear dependent of the resistivity on temperature is observed only for the samples; $x=0.2$ and $x=0.8$. The linear dependent of the resistivity on temperature for the samples; $\mathrm{x}=0.4$ and $\mathrm{x}=0.6$ is observed only 
from $\mathrm{T}=294 \mathrm{~K}$ to $\mathrm{T}=383 \mathrm{~K}$ and $435 \mathrm{~K}$, respectively. As it is well-known, the electric transport in the present case occurs through the oxygen ions so that the length of this bond is very important in the evaluation of the electrical properties. The Fe-O bond lengths are listed in Table (4). The mean value of bond length for the $\mathrm{x}=0.2$ and $\mathrm{x}=0.4$ samples are identical $(1.9753 \AA)$ which gives a reason why these samples have the same order of resistivity (few $\Omega . \mathrm{cm})[10]$. For the samples with $\mathrm{x}=0.6$ and $\mathrm{x}=0.8$, table 4 shows that the bond length increased which explains the rapid increase of resistivities for these samples with increasing. The increase of the distance between atoms accompanying the increase in the iron concentration leads to a decrease in the overlap between the atomic energy levels. So it is expected that the increase of iron concentration leads to an increase in the activation energy EA. The relation between EA and the volume of unit cell for all $\mathrm{x}$ is illustrated in Fig. (3) confirms such a result. Thus one concludes that the activation energy EA is directly proportional to the volume of the unit cell.

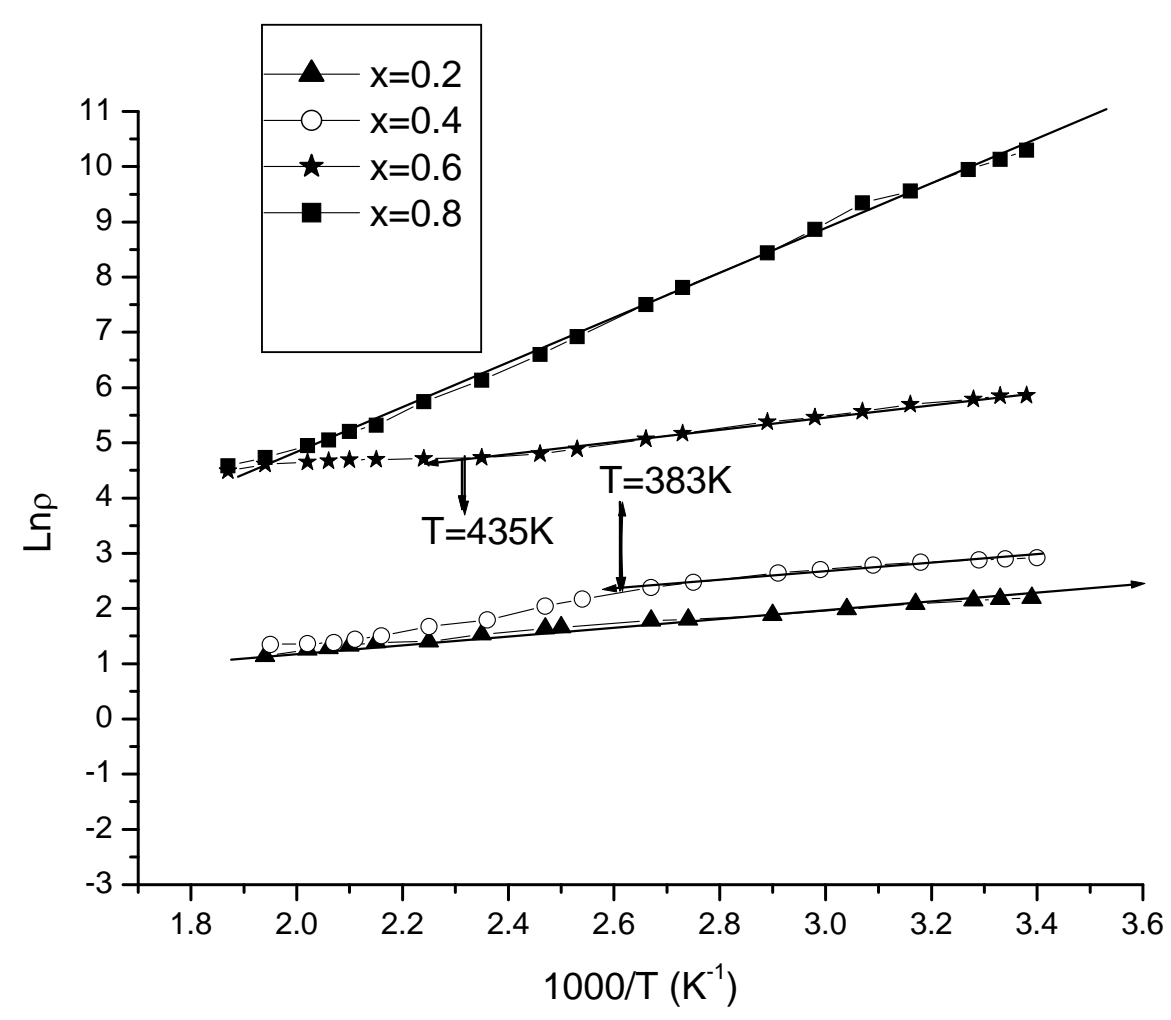

Fig.(2): Resistivity - temperature dependence of $\mathrm{Nd}_{0,65} \mathrm{Sr}_{0,35} \mathrm{Mn}_{1-\mathrm{X}} \mathrm{Fe}_{\mathrm{X}} \mathrm{O}_{3}$. 
Table (4): The Fe-O bond length $(\AA)$ for $\mathrm{Nd}_{0.65} \mathrm{Sr}_{0.35} \mathrm{Mn}_{1-x} \mathrm{Fe}_{x} \mathrm{O}_{3}$.

\begin{tabular}{|c||c|c|c|c|}
\hline \hline $\mathbf{x}$ & $\mathbf{0 . 2}$ & $\mathbf{0 . 4}$ & $\mathbf{0 . 6}$ & $\mathbf{0 . 8}$ \\
\hline \hline \multirow{2}{*}{$\mathrm{Fe}-\mathrm{O}(1)$} & $\begin{array}{c}1.9954 \\
\mathrm{Fe}^{\mathrm{i}}, \mathrm{O}(1)^{\mathrm{iv}}\end{array}$ & $\begin{array}{c}1.9347 \\
\mathrm{Fe}^{\mathrm{ii}}, \mathrm{O}(1)^{\mathrm{v}}\end{array}$ & $\begin{array}{c}1.9451 \\
\mathrm{Fe}^{\mathrm{i}}, \mathrm{O}(1)^{\mathrm{vi}}\end{array}$ & $\begin{array}{c}1.9413 \\
\mathrm{Fe}^{\mathrm{i}}, \mathrm{O}(1)^{\mathrm{vii}}\end{array}$ \\
\hline \multirow{2}{*}{$\mathrm{Fe}-\mathrm{O}(2)$} & $\begin{array}{c}1.7124 \\
\mathrm{Fe}^{\mathrm{i}}, \mathrm{O}(2)^{\mathrm{viii}}\end{array}$ & $\begin{array}{c}1.7704 \\
\mathrm{Fe}^{\mathrm{ii}}, \mathrm{O}(2)^{\mathrm{x}}\end{array}$ & $\begin{array}{c}1.2207 \\
\mathrm{Fe}^{\mathrm{i}}, \mathrm{O}(2)^{\mathrm{xi}}\end{array}$ & $\begin{array}{c}1.4931 \\
\mathrm{Fe}^{\mathrm{i}}, \mathrm{O}(2)^{\mathrm{xiii}}\end{array}$ \\
\hline \multirow{2}{*}{$\mathrm{Fe}-\mathrm{O}(2)$} & $\begin{array}{c}2.2182 \\
\mathrm{Fe}^{\mathrm{i}}, \mathrm{O}(2)^{\mathrm{ix}}\end{array}$ & $\begin{array}{c}2.1164 \\
\mathrm{Fe}^{\mathrm{i}}, \mathrm{O}(2)^{\mathrm{x}}\end{array}$ & $\begin{array}{c}3.2971 \\
\mathrm{Fe}^{\mathrm{i}}, \mathrm{O}(2)^{\mathrm{xii}}\end{array}$ & $\begin{array}{c}4.3408 \\
\mathrm{Fe}^{\mathrm{iii}}, \mathrm{O}(2)^{\mathrm{xiv}}\end{array}$ \\
\hline$<\mathrm{Fe}-\mathrm{O}>$ & 1.9753 & 1.9754 & 2.1543 & 2.5917 \\
\hline
\end{tabular}

Symmetry codes:

(i) $0,0.5,0.5$; (ii) $0.5,0.5,1.0$; (iii) $0.5,0.5,0$; (iv) $0.099,0.25,0.4880$; (v) $0.482,0.75,0.9962$; (vi) $0.0053,0.75,0.5418$; (vii) $0.0137,0.25,0.5352$; (viii) 0.2517, 0.4663, 0.681; (ix) 0.2483, 0.5337, 0.181; (x) 0.2398, 0.5046, 0.1944; (xi) $0.2126,0.5445,0.5718$; (xii) $0.2874,0.4555,0.9718$; (xiii) $0.1542,0.4746$, 0.2784 ; (xiv) $0.3458,0.5254,0.7784$

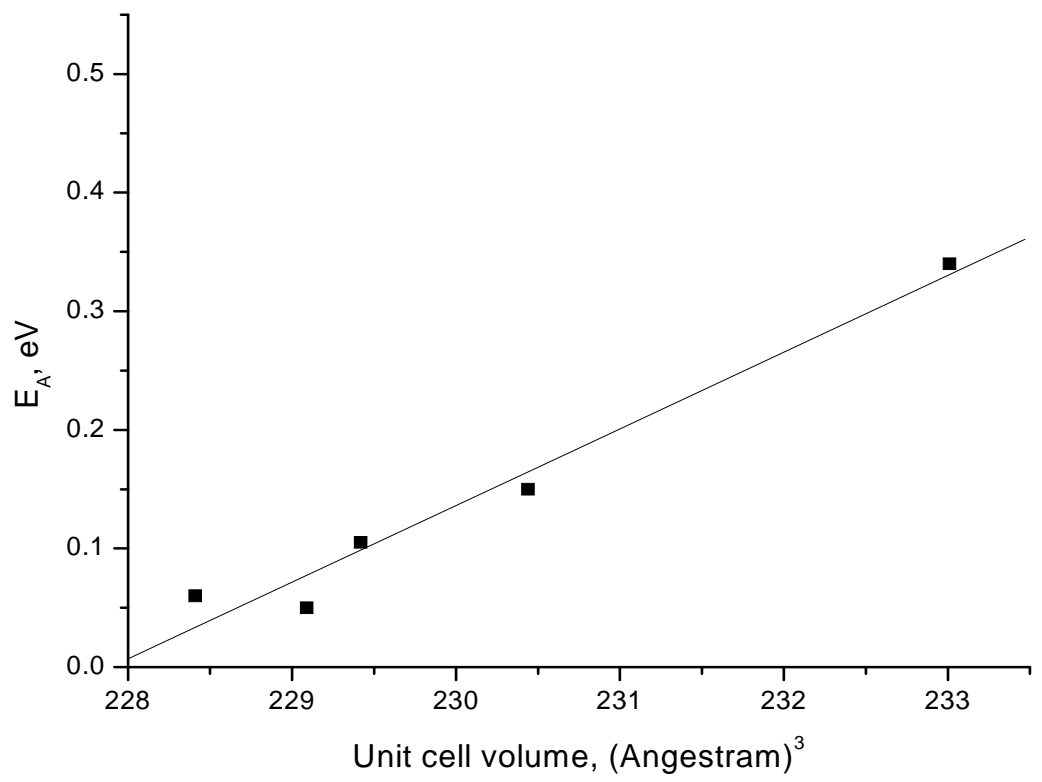

Fig. (3): The activation energy $E_{A}$ as a function of unit cell volume; the closed square is the experimental and the solid line is the calculated.

The neutron diffraction patterns of the $\mathrm{Nd}_{0.65} \mathrm{Sr}_{0.35} \mathrm{Fe}_{0.6} \mathrm{Mn}_{0.4} \mathrm{O}_{3}$ sample, using multi detector diffractometer, at different temperatures $(120 \mathrm{~K}$, $287 \mathrm{~K}$ and $520 \mathrm{~K}$ ) are illustrated in Fig. (4). The magnetic structure analysis of these diffraction patterns shows that this compound has ferromagnetic character at $120 \mathrm{~K}$ and $287 \mathrm{~K}$ temperatures. The analysis allows to determine the projections of the magnetic moment at $\mathrm{x}-, \mathrm{y}-$ and $\mathrm{z}$-axis and the resulting 
magnetic moment (see Table (5)). The resulting magnetic moments at $120 \mathrm{~K}$ and $287 \mathrm{~K}$ are $2.6 \mu \mathrm{B}$ and $2.1 \mu \mathrm{B}$, respectively. The projections of the magnetic moment in $\mathrm{x}$ and $\mathrm{z}$ - directions have the same value and orientation $(0.1 \mu \mathrm{B}$ and $-0.6 \mu \mathrm{B}$ ) while there is a difference only in the value of magnetic moment in y-projection where it takes $2.5 \mu \mathrm{B}$ at $120 \mathrm{~K}$ and $1.9 \mu \mathrm{B}$ at $287 \mathrm{~K}$. In the case of the $\mathrm{T}=520 \mathrm{~K}$, there is a change in the magnetic ordering where non-collinear magnetic ordering of $1.2 \mu \mathrm{B}$ resulting magnetic moment is obtained. The projection of magnetic moment in $\mathrm{x}$-axis is equal to zero and in $\mathrm{y}$-axis is equal to $1 \mu \mathrm{B}$ while in $\mathrm{z}$-axis there are two opposite values $\pm 0.7 \mu \mathrm{B}$ between them angle of $73^{\circ}$. From the above, one can say that phase transition, from the pure ferromagnetic ordering into the non-collinear ordering (weak ferromagnetic), occurs near the $520 \mathrm{~K}$ temperature.

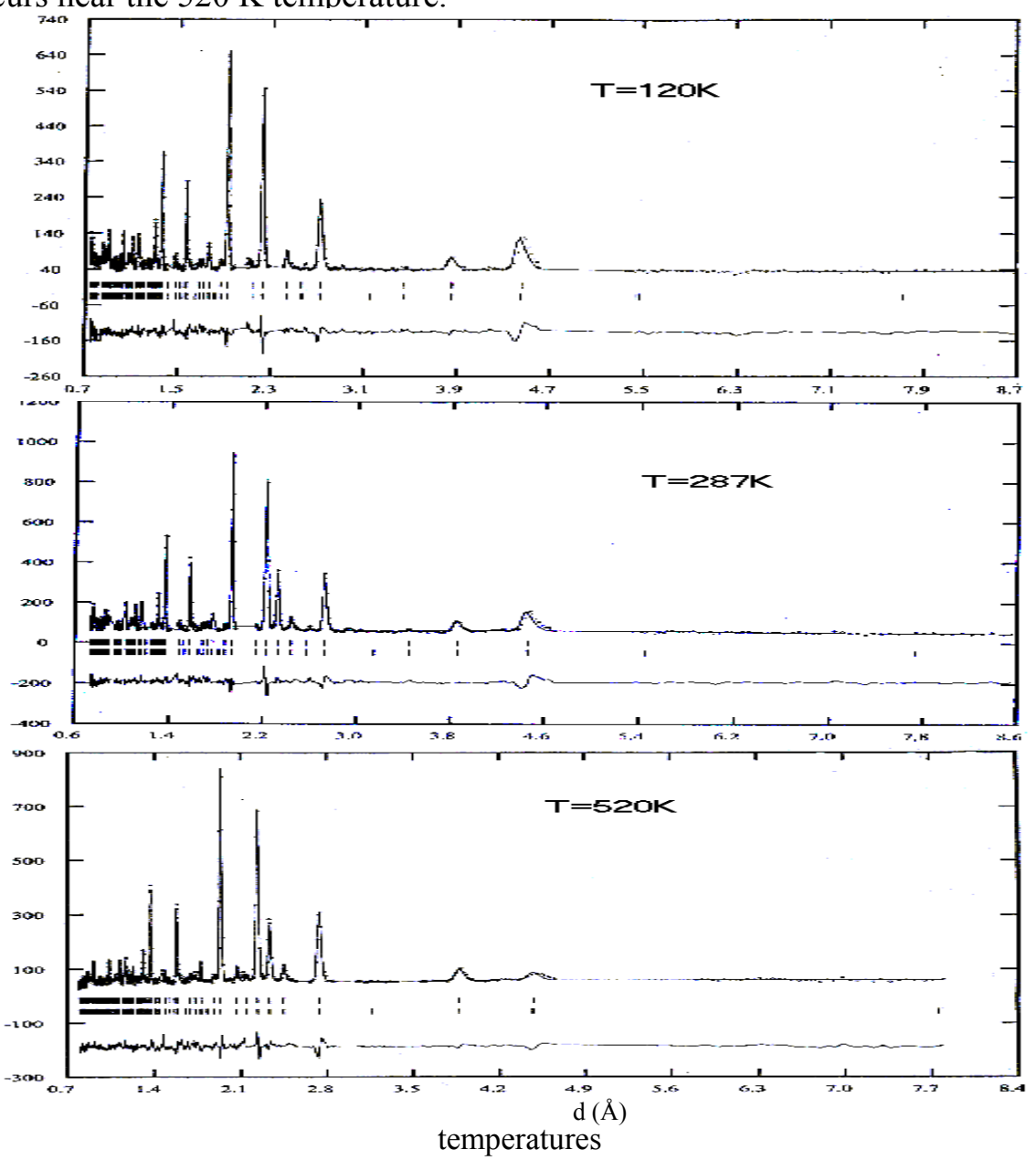

Thermo-magnetic measurements are shown in Fig.(5). The magnetic behaviour in the present case is very interesting. The more interesting 
compounds are those with $\mathrm{x}=0.2,0.4$ and 0.6 because they have multimagnetic states. The multi-magnetic states appear either as a result of the inhomogeneity of the iron distributions in the next near neighboring $[11,12]$ or as a result of the coexistence of ferromagnetic and weak ferromagnetic ordering. The ferromagnetic ordering appears as a result of the $\mathrm{Mn}^{3+}-\mathrm{O}-\mathrm{Mn}^{4+}$ and $\mathrm{Fe}^{3+}-\mathrm{O}-$ $\mathrm{Mn}^{3+}$-interactions, while the antiferromagnetic ordering as a result of $\mathrm{Fe}^{3+}-\mathrm{O}-$ $\mathrm{Fe}^{3+}$ and $\mathrm{Mn}^{3+}-\mathrm{O}-\mathrm{Mn}^{3+}$ interactions. As a result of the competition between both the ferromagnetic and the antiferromagnetic ordering, the spin glass phase will appear [13-15]. So one can say that the coexistence of the ferromagnetic and weak ferromagnetic ordering is an indication for multi-magnetic states in such compounds while for the sample with $\mathrm{x}=0.8$ there is only weak ferromagnetic ordering with Curie temperature near $676 \mathrm{~K}$. From the magnetizationtemperature dependence that is illustrated in Fig (5), it is clear that for $\mathrm{x}=0.2$, 0.4 and 0.6 there are two phase transition points. These temperatures are indicated by arrows in Fig. (5). These results are in a good agreement with those obtained from neutron diffraction for $\mathrm{x}=0.6$, where there are two phase transition points; the first transition from ferromagnetic into non-collinear ordering near $500 \mathrm{~K}$ and the second from non-collinear into paramagnetic phase near $660 \mathrm{~K}$. According to the Mössbauer spectroscopy measurements at different temperatures for $\mathrm{x}=0.4$ and 0.6 samples the multi-magnetic states are confirmed [7]. The magnetization temperature dependence behaviour of $\mathrm{Nd}_{0.65} \mathrm{Sr}_{0.35} \mathrm{Mn}_{1-\mathrm{x}} \mathrm{Fe}_{\mathrm{x}} \mathrm{O}_{3}$ in the present case is in a good agreement with those reported for $\mathrm{La}_{0.8} \mathrm{Sr}_{0.2} \mathrm{Mn}_{0.8} \mathrm{Ni}_{0.2} \mathrm{O}_{3}$ and $\mathrm{La}_{0.7} \mathrm{Sr}_{0.3} \mathrm{Mn}_{0.8} \mathrm{Ni}_{0.2} \mathrm{O}_{3}$ [14], where the antiferromagnetic order is existed in addition to ferromagnetic order and the interaction between them leads to appearance of spin glass $[14,15]$.

\section{Conclusions:}

- The crystal structure of $\mathrm{Nd}_{0.65} \mathrm{Sr}_{0,35} \mathrm{Mn}_{1-x} \mathrm{Fe}_{x} \mathrm{O}_{3}$, for all $x$, does not change and have the orthorhombic distortion perovskite-like structure with Pnma space group.

- The activation energy is directly proportional to the unit cell volume.

- The transition from the pure ferromagnetic ordering into the non-collinear ordering (weak ferromagnetic) occurs near $520 \mathrm{~K}$ for $\mathrm{Nd}_{0.65} \mathrm{Sr}_{0.35} \mathrm{Fe}_{0.6} \mathrm{Mn}_{0.4} \mathrm{O}_{3}$. 

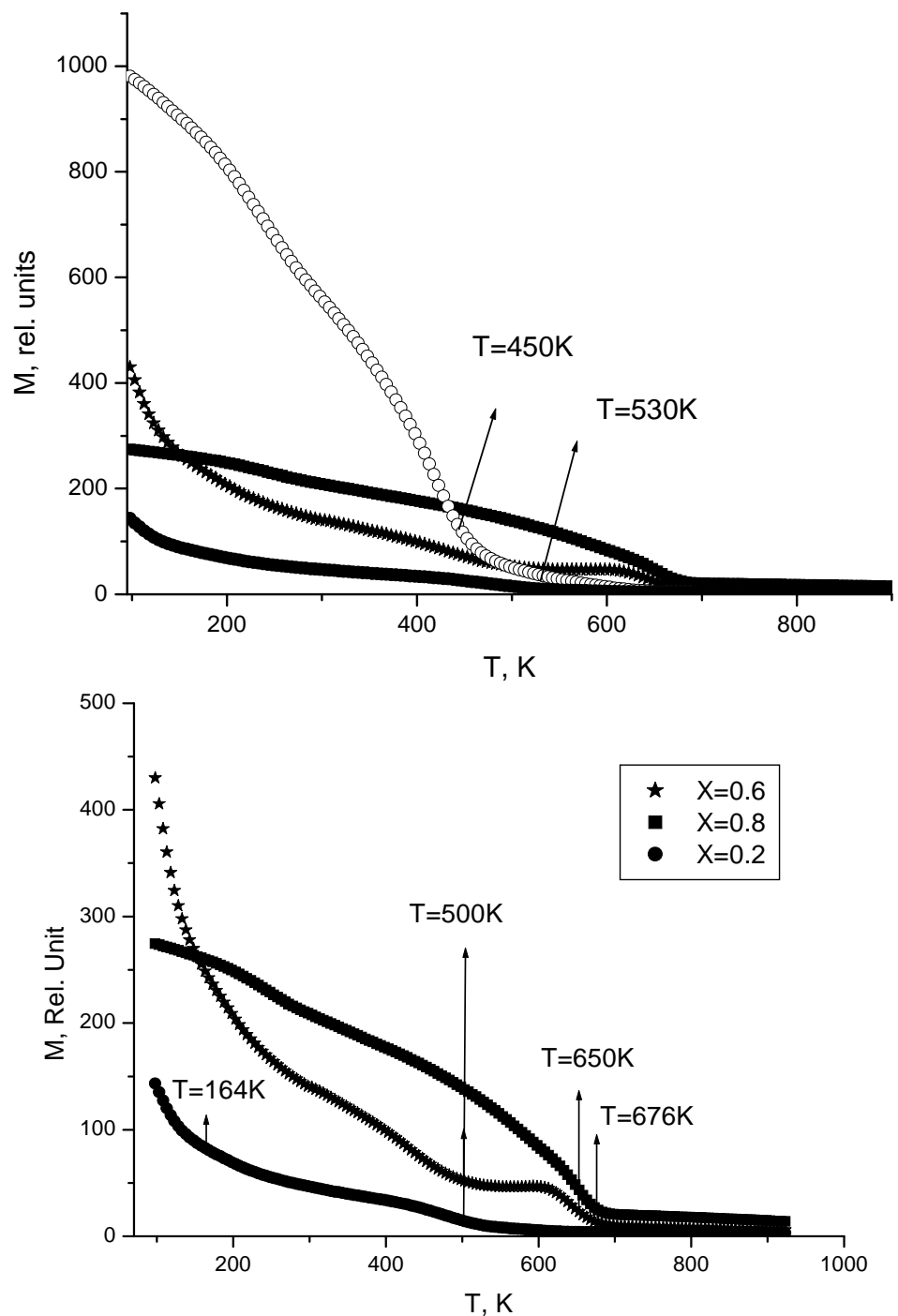

Fig. (4): The magnetization-temperature dependence.

\section{References:}

1. M. Marezio, J. P. Remeika, P.D. Dernier, Acta Cryst. B.26, 2008 (1970).

2. G. H. Jonker and J. H. van Santen, Physica, 16, 337 (1950).

3. G. H. Jonker and J. H. van Santen, Physica, 16, 599 (1950).

4. C. Zener, Phys. Rev. 82 (1951) 403.

5. V. B. Zlokazov and V. V. Chernyshev, J. Appl. Cryst. 25, 447 (1992).

6. J. Rodriguez-Carvajal, Physica B. 192, 55 (1993). 
7. Sh. Sh. Bashkirov, I. A. Abdel-Latif, A. Yousif, et al., Abstract book of ICAME, Muscat, (2003).

8. J. L. Garacia-Monoz and J. Rodriguez-Carvajal, Phys. Rev. B46 (8), 4414 (1992).

9. V. A. Strelsov and N. Ishizawa, Acta Cryst. B55, 1 (1999).

10. V. V. Parfenov, Sh. Sh. Bashkirov and I. A. Abdel-Latif, Proc. Inter. Conf. Of Physics of Electronic Materials, Kaluga, 224 (2002).

11. Sh. Sh. Bashkirov, V.V. Parfenov, A. A. Valiullin, A.S. Khramov, V.A. Trounov, A.P.Smirnov, I. A. Abdel-Latif, Izv. RAS Physical series 67, 1072 (2003).

12. Sh. Sh. Bashkirov, V. V. Parfenov, I. A. Abdel-Latif, L. D. Zaripova, J. Alloys and Compounds 287, 70 (2005).

13. J. Feng and L. Hwang, Appl. Phys. Lett. 75 (11), 1592 (1999).

14. T. Terai, T. Kakeshita, T. Fukuda, et al., Phys. Rev. $B 58$ (22), 14908 (1998).

15. T. K. Solovykh, I. O. Troyanchuk, D. D. Khalayavin, et al., phys. stat. sol. (a) 172, 485 (1999). 